\begin{tabular}{|l|l|}
\hline $\begin{array}{l}\text { La querella intelectual del quechuaymara Fausto Reinaga contra Fernando Diez de } \\
\text { Medina }\end{array}$ & Titulo \\
\hline Ticona Alejo, Esteban - Autor/a; & Autor(es) \\
\hline $\begin{array}{l}\text { De Raíz Diversa. Revista Especializada en Estudios Latinoamericanos (Vol. 1 no. 1 } \\
\text { abr-sep 2014) }\end{array}$ & En: \\
\hline México D.F. & Lugar \\
\hline $\begin{array}{l}\text { Programa de Posgrado en Estudios Latinoamericanos, Universidad Nacional } \\
\text { Autónoma de México }\end{array}$ & Editorial/Editor \\
\hline 2014 & Fecha \\
\hline & Colección \\
\hline $\begin{array}{l}\text { Intelectuales; Díez de Medina, Fernando; Política; Quechuas; Aymaras; Reinaga, } \\
\text { Fausto; AYLLU - Forma de comunidad familiar extensa-región andina; Bolivia; }\end{array}$ & Temas \\
\hline Artículo & Tipo de documento \\
\hline "http://biblioteca.clacsoedu.ar/Mexico/ppel-unam/20160614023404/Ticona.pdr" & URL \\
\hline $\begin{array}{l}\text { Reconocimiento-No Comercial-Sin Derivadas CC BY-NC-ND } \\
\text { http://creativecommons.org/licenses/by-nc-nd/2.0/deed.es }\end{array}$ & Licencia \\
\hline
\end{tabular}

Segui buscando en la Red de Bibliotecas Virtuales de CLACSO http://biblioteca.clacso.edu.ar

Consejo Latinoamericano de Ciencias Sociales (CLACSO)

Conselho Latino-americano de Ciências Sociais (CLACSO)

Latin American Council of Social Sciences (CLACSO)

www.clacso.edu.ar

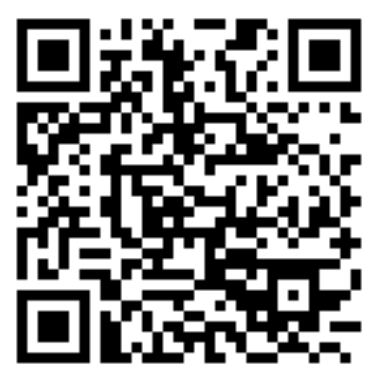




\title{
La querella intelectual del quechuaymara Fausto Reinaga contra Fernando Diez de Medina
}

\author{
Esteban Ticona Alejo *
}

\begin{abstract}
Resumen. El quechuaymara boliviano Fausto Reinaga tuvo en su vida intelectual varios debates y polémicas. Su disputa con el escritor Fernando Diez de Medina, posiblemente sea el más conocido y difundido. Reinaga escribió un libro en 1964 bajo el título de El indio y el cholaje boliviano. Proceso a Fernando Diez de Medina, motivo de este breve artículo. Esta obra está situada en su etapa de pensador marxista, aunque su contenido adquiere "la voz y el pensamiento indio" contra el escritor mestizo boliviano Diez de Medina.
\end{abstract}

Palabras Clave: Fausto Reinaga, Fernando Diez de Medina, política intelectual, Quechua, Aymara.

Abstract: The Bolivian quechuaymara Fausto Reinaga in his intellectual life held several debates and controversies. Maybe his quarrel with the writer Fernando Diez de Medina is the best known and disseminated. Reinaga wrote a book in 1964 under the title of The Indian and Bolivian cholaje. Processing Fernando Diez de Medina. Our proposal is to show that his work is located in the stage of Marxist thought, although its content acquires "the voice and the Indian thought" against the Bolivian mestizo writer Diez de Medina.

Keywords: Fausto Reinaga, Fernando Diez de Medina, intellectual politics, Quechua, Aymara.

Recibido: 11 de noviembre de 2013. EnTRegado: 20 de enero de 2014.

\section{¿QUIÉN FUE FAUSTO REINAGA?}

$\mathrm{F}$ austo Reinaga Chavarría fue quechua y aymara o quechuaymara, como se identificaba; vivió entre 1906 y 1994. Nació el 27 de marzo en el Jatum ayllu Macha de la provincia Chayanta del Norte de Potosí y murió el amanecer del 19 de agosto en la ciudad de La Paz, Bolivia. Aprendió a leer y escribir el castellano en su adolescencia, enfrentando mil vicisitudes logró dominarlos hasta llegar a la universidad y graduarse en derecho en 1936. Fue escritor, ensayista, filósofo, político, activista e ideólogo indíge-

* Docente en la Universidad Mayor de San Andrés (Bolivía), <esteban.ticona@gmail.com>. 
na; autor de 32 obras publicadas y varios textos inéditos. Su abundante producción intelectual dio origen al pensamiento político indígena contemporáneo, denominado el indianismo.

Sobre la trayectoria intelectual de Reinaga no existen estudios profundos realizados en Bolivia. Su original producción continúa siendo tratada muy superficialmente, a excepción del indigenista ecuatoriano Guillermo Humberto Mata (1968), quien escribió algunos fragmentos sobre su vida a finales de los años sesenta. Algunos artículos de prensa, uno que otro folleto y el citarlo - muchas veces - en algún evento académico o político son formas de recordarlo (Oporto, 1994; Martínez, 1999; Stephenson, 2003; Reinaga, 2004: Salas, 2005; Alvizuri, 2009).

Gran parte de la obra de Reinaga fue publicada en Bolivia, durante sus largos años de producción y lucha, aunque como consecuencia del colonialismo intelectual fue casi silenciada y hoy circula alguna que otra como La Revolución india (1970, 2001 y 2007) y la Tesis india (1971). ${ }^{1}$

En estos últimos años existe un interés particular de estudiar a Reinaga en varios países. Por ejemplo, la tesis doctoral del argentino Gustavo Cruz titulada Los senderos históricos-políticos e ideológicos-filosóficos de Fausto Reinaga (1906-1994), que indaga la relación conflictiva entre marxismo e indianismo en Fausto Reinaga. La investigación contó con el auspicio de la Universidad Nacional Autónoma de México, en 2011. Una tesis de maestría de María Elena Oliva, titulada La negritud, el indianismo y sus intelectuales: Aimé Césaire y Fausto Reinaga, es una mirada comparativa entre negritud e indianismo, mediante la búsqueda y selección de textos que dieran cuenta del desarrollo de ambos discursos, como ¿Cuál es la particularidad de la negritud y el indianismo?, ¿qué definición de identidad nos entregan?, ¿cómo problematizan el racismo y el sistema colonial?

A iniciativa de algunos activistas aymaras radicados en Europa, como Mario Gutiérrez, fundador del grupo musical Ruphay, se tradujo al francés su obra América India y Occidente (1974), bajo el nombre de L'Amerique Indienne et L' Occident (1979), y al alemán como América india und das Abendland (1980). Además, con auspicio de la Vicepresidencia del Estado Plurinacional de Bolivia, el Convenio "Andrés Bello" y la carrera de Filosofía de la UMSA, está en curso la publicación de las obras completas en cuatro tomos de Fausto Reinaga.

1 En el anexo incluimos los títulos de las obras publicadas por Reinaga. 


\section{LA QUERELLA CONTRA FERNANDO DIEZ DE MEDINA}

Fernando Diez de Medina nació en La Paz en 1908 y murió en $1990 .^{2} \mathrm{Al}$ indagar cómo lo calificaba el medio intelectual del país, nos topamos con varias apreciaciones, como la siguiente: "Ensayista, poeta, crítico, dramaturgo, biógrafo, periodista, cuentista, novelista, conferencista, mitologista, político y diplomático..” (Guzmán, 1975: 255).

Reinaga escribió en 1964 el libro El indio y el cholaje boliviano. Proceso a Fernando Diez de Medina. Obra expuesta en dos partes. La primera parte se divide en los siguientes apartados: “Qué es un escritor?”; "El velero matinal"; "Nayjama”, “Thunupa y el estetismo comercial”; "Franz Tamayo-Hechicero del ande y la revolución india"; "Literatura boliviana y el pensamiento cholaje republicano". La segunda parte contiene "Fernando Diez de Medina, el político"; "Diez de Medina y la cuestión portuaria"; "Sariri y Fantasía coral”; "La reforma educacional: el alma del cholo y el alma del indio"; "El valor del propio ejemplo".

¿Por qué don Fausto escribió el libro citado? Al decir de Reinaga:

Este ensayo es el primer estudio de la sociedad boliviana desde un punto de vista indio; sociedad en la que tras paciente investigación y experiencia no hemos encontrado más que dos fuerzas étnicas, dos razas, en perpetua lucha: indios y cholos (Reinaga, 1964: 5).

Es la obra del primer escritor indio del siglo XX, que interpela el pensamiento y la práctica de la élite boliviana entre 1930 y 1970. Reinaga nos cuenta cuál era la actitud de estas élites de la ciudad de La Paz a finales del siglo XIX y principios del XX:

Después de la Revolución federal de $1898,{ }^{3}$ nacer en La Paz era un privilegio. El paceño se desempeñaba respecto los habitantes del "interior" como un terrateniente gamonal respecto a sus pongos-siervos. Esta situación hoy se halla aminorada, pero ello no significa que se haya superado y desapare-

2 Citamos algunas de sus obras publicadas: El velero matinal (1935); Franz Tamayo, el hechicero del Ande (1942); Thunupa (1942); Pachakuti (1948); Siripaka (1949); Nayjama (1950); Literatura boliviana (1953); Sariri (1954); Mateo Montemayor (1969); Ollanta el jefe Colla (1970); El general del pueblo (1972); La teogonía andina (1973).

3 La Revolución Federal de 1898 fue una lucha económica regional de las élites del sur (Sucre) y del norte ( $\mathrm{La} \mathrm{Paz}$ ). El resultado fue el triunfo del norte, con la decisiva participación del movimiento indígena lidereado por Pablo Zárate Willka. Además, el triunfo posibilitó el traslado de la sede de gobierno de Sucre a la ciudad de La Paz (Condarco Morales, 1966/1983). 
cido; existe un aldeano regionalismo subterráneo, especialmente en las capas sociales de la burguesía feudal y clase media; a tal punto (ahora 1964) que nadie puede ser ni Rector de la Universidad ni Alcalde Municipal si no es paceño de nacimiento (Reinaga, 1964: 23).

En El indio y el cholaje boliviano. Proceso a Fernando Diez de Medina (1964), Reinaga dice:

Diez de Medina, se halla dominado por una "idea fija”, idea que no le deja ni a sol ni a sombra. Fernando Diez de Medina, piensa que Fernando Diez de Medina es grande, una luminosa conciencia. Un sabio y un humanista. Y, como los humanistas del Renacimiento, cree él que ninguna disciplina mental se le escapa; cree él que es filósofo, poeta, científico, historiador, cuentista, ensayista, crítico, político, conductor de la "Revolución", indigenista, sociólogo, maestro, financista, etc. (Reinaga, 1964: 67).

Reinaga nos cuenta por qué se atrevió a procesar intelectualmente a Diez de Medina:

Enjuiciamos hoy a Fernando Diez de Medina, porque introspectivamente en él se revelan los genuinos rasgos somáticos y se acusan con singularidad inequívoca las características morales y psíquicas del cholaje boliviano de nuestro tiempo. Y porque es el escritor más prolífero y político más activista, pero sobre todo porque, gracias a la propaganda tarifada, ha devenido como el "escritor indigenista" de "reputación universal" (Reinaga, 1964: 13).

Pero ¿qué es el indigenismo boliviano para Reinaga? "El indigenismo es una corriente literaria y política, producida y salida de la pluma del cholaje intelectual boliviano acerca del indio" (Reinaga, 1964: 13).

A pesar de su origen, Reinaga dice que el indigenismo debería ser un proindio; pero Diez de Medina asegura lo contrario:

Los indigenistas de cualquier ángulo y latitud ideológica se sitúan en un punto de vista PROINDIO; y sólo Fernando Diez de Medina, no; porque el suyo es un punto de vista ANTI-INDIO. Y "su" indigenista reputación es una aberración (Reinaga, 1964: 13).

Reinaga, frente al indigenismo del cholaje, apuesta por el indianismo: "La literatura india o el indianismo es la literatura producida por el intelectual auténticamente indio" (Reinaga, 1964: 13).

Don Fausto no cree que sólo los indios tengan la exclusividad en el indianismo, sino que el cholaje pro-indio también puede ser indianista: 
"Conociendo y comprendiendo la razón de la causa india, el cholaje intelectual puede crear y hacer una literatura india" (Reinaga, 1964: 13).

Reinaga desbarata qué hay detrás del indigenismo de Fernando Diez de Medina:

El cholaje desde aquel sábado 6 de agosto de 1825 hasta nuestros días, ha esgrimido un pensamiento y una actitud de discriminación y segregación racial con respecto al indio; al cual esclavizando, asesinando, robándole sus tierras y su cultura, lo ha sometido a una oprobiosa condición infra-humana peor que en la Colonia; ya que en aquel periodo, sobre la cabeza de los españoles venidos de la Península, pendía como la espada de Damocles: el respeto y la obediencia al Rey, el miedo y temor a Dios, y encima al juez de la conciencia, que bajo estricto control del confesionario, vigilaba pensamientos y actos, razón por la que la absolución no era cosa fácil de alcanzar; muchas veces era negada hasta en artículo de muerte (Reinaga, 1964: 14).

Reinaga está convencido de que Diez de Medina es más un político que un intelectual:

Y con relación a los intereses y los derechos de la Nación boliviana, el cholaje (escudado detrás de cuanta ideología llegada de Europa, disfrazado ora liberal, constitucional, republicano, nacionalista, socialista, fascista o "comunista") ha manejado el destino de este país con la filosofía de las tripas, el falo y la vagina (Reinaga, 1964: 14).

El enjuiciamiento de Reinaga a Diez de Medina es como el despertar indio hacia la revolución:

[...] es el primer destello de aquella aurora roja que anuncia el despertar del indio, este libro es una chispa desprendida del fuego que arde y crepita en la entraña de la raza, fuego que flameará la llamarada de la REVOLUCIÓN INDIA, destinada por la dialéctica de la historia a salvar Bolivia (Reinaga, 1964: 16).

Fernando Diez de Medina fue un político e indigenista conservador, perteneciente a las élites criolla-mestizas del país. Ocupó cargos muy importantes como la Secretaría General del Banco Central de Bolivia en 1936, ministro de educación del gobierno del Movimiento Nacionalista Revolucionario (MNR) entre 1956 y 1957. Fue embajador de Bolivia ante el Vaticano en 1958. Asesor del gobierno militar de René Barrientos Ortuño, en 1964 y 1969; y en 1967 fue ministro sin cartera del mismo gobierno 
de Barrientos. En 1951 obtuvo el Premio Nacional de Literatura (Guzmán, 1975: 255-256).

Para Fausto Reinaga, Diez de Medina gozó de muchos privilegios y poder por su origen social y de ninguna manera por su capital de intelectual:

Fernando Diez de Medina, producto de la flor y nata de la "sociedad" paceña, luciendo una piel blancoide, provisto de los congénitos derechos y privilegios, y sobre todo en posesión del Poder casi absoluto de la raza opresora, ingresa en la República de Letras. Y desde este momento su estrella polar le guía con tanta luminosidad y seguridad, que Fernando Diez de Medina (no había ya duda) se siente un elegido de los dioses... (Reinaga, 1964: 24).

Fausto Reinaga no concibe que un intelectual no tenga un compromiso social profundo con su tiempo y con los problemas más acuciantes del mundo. Este razonamiento hace que se pregunte ¿qué es un escritor? Reinaga encuentra un sinfín de contradicciones en la vida intelectual de Diez de Medina:

En el oleaje enfurecido de los mares humanos de nuestro tiempo, debería ser el escritor brújula y faro; pasión prometheica en un mundo de destrucción y terror, razón que no retrocede ante la galaxia sideral ni ante el espectáculo de la energía atómica (Reinaga, 1964: 17).

Continúa reflexionando sobre el papel de escritor:

Y los hombres de la tierra, tienen sed de verdad y justicia. Y hay escritores, aquellos precisamente que son los llamados a abrir la senda hacia el bien, la paz, la justicia y la libertad, voluntaria e involuntariamente enceguecidos y ensordecidos, prostituidos y prostituyendo su noble misión, vencidos por el bolso estomacal, viven de rodillas ante el "becerro de oro" (Reinaga, 1964: 18).

Para Fausto Reinaga es inconcebible que el escritor no haga una lectura de lo que sucede con la humanidad y sus problemas. Dice específicamente:

No es concebible, cuesta trabajo pensar que un escritor de nuestro tiempo no sienta, no se aperciba de los riesgos que rodean no sólo la vida humana, sino la vida en sí. El producto de infinitos milenios de evolución o de revolución que remataron en el advenimiento de un cerebro pensante y de una conciencia luz: el mayor milagro que se ha producido en el Universo. Este milagro hoy, se halla asediado, amenazado de una total aniquilación. El escritor, debe ponerse en guardia del hombre. El 
que no parte de esta premisa, camina de uno u otro modo en las sendas del crimen de lesa-humanidad (Reinaga, 1964: 19 y 20).

Reinaga exige que los escritores tengan un compromiso con su realidad; como la apuesta por la verdad y la libertad:

El escritor tiene en sí, en sus pensamientos y actos, una sagrada misión en la vida: la misión de la verdad y la libertad, y la lucha por la organización socialista de la sociedad humana. La libertad, la verdad y el socialismo, constituyen la luz del espíritu y el fuego del corazón del hombre con la pluma. En consecuencia, el escritor de conciencia, hoy más que en ninguna época, debe ser un revolucionario cabal. Bebiendo horizonte tras horizonte el pensamiento va más allá de la sociedad sin clases del futuro (Reinaga, 1964: 21 y 22).

Es importante mencionar que los conceptos de verdad y libertad sufrirán cambios en su proceso de pensamiento. Pero para Fausto Reinaga no se modifica la lucha de los pueblos y particularmente del pueblo indio. Además se pregunta ¿Por qué y para quién escribimos?

Estos conceptos se han hecho sangre de mi sangre y viven en mi vida como substancia fertilizante de mi espíritu indio kolla, que siente y apercibe la problemática de un pueblo, de una raza poderosa que ha subsistido arrastrando una existencia infame, abyecta, cuasi animal por cuatro siglos y medio, pero que ahora el soplo huracanado de la Revolución de nuestro tiempo, arrojando lejos la somnolencia bestial, se dispone a entrar en la batalla por la conquista de su propia libertad. Ante este acontecimiento que golpea ya la conciencia y hiere como el duro cierzo andino la epidermis europeizada de la sensibilidad chola, ¿qué actitud adoptamos los escritores de Bolivia? ¿Escribimos? ¿Por qué escribimos? ¿Para quién escribimos? (Reinaga, 1964: 22-23).

Fausto Reinaga encuentra en aquel ego intelectual exacerbado de Diez de Medina una clara práctica de colonialismo intelectual:

El escritor de nuestro tiempo, ya dijimos, se halla "comprometido". O pertenece al pasado o pertenece al futuro. En los países pequeños y avasallados como el nuestro, causa estragos la "colonización intelectual" (Reinaga, 1964: 24).

Está convencido de que Diez de Medina es un simple imitador de ideas foráneas:

Los escritores de Bolivia han vivido y viven de aquello que menciona Henri de Man con el nombre de "experiencias por sustitución". Esto es, que sin 
saber nada, ni ver nada, ni sentir nada, ni comprender nada de Francia o de Rusia, con simples datos de libro, revista, periódico o radiales, tejen conceptos, calcan ideas e imágenes y los meten en la entraña de su vida subjetiva y objetiva, desenvolviendo de este modo el proceso todo de su producción intelectiva (Reinaga, 1964: 25).

Continúa Reinaga en esta línea de reflexión:

Desde la fundación de la República hasta nuestros días, los escritores de Bolivia han hecho el triste papel de cipayos ideológicos de los escritores de las Metrópolis. Fueron escritores títeres y "comprometidos" hasta el tuétano de sus huesos. Pensaron y sintieron toda la vida con la cabeza y el corazón de la gente de allende los mares. He aquí la razón de que las ideas y conceptos de la libertad y democracia hicieran un carnaval perpetuo. La libertad y la democracia fueron las máscaras de la opresión más feroz y de la tiranía caciquista más bárbara (Reinaga, 1964: 25).

En un intento general y crítico, Reinaga describe las obras principales de Fernando Diez de Medina:

La influencia telúrica ha sido fatal para Diez de Medina. Desde "El velero matinal" hasta "Bolivia y su destino", su pensamiento es un pensamiento monolítico. Todo lo que se registra en sus "veinte lujosas obras" es una repetición que aturde; estos libros son como las salas cinematográficas; "Thunupa", "Nayjama”, "Sariri", "Aynoka", "El arquero", "Bolivia y su destino", exhiben una sola y misma película: el pensamiento pétreo de Diez de Medina. El espíritu y el sentimiento de Diez de Medina se han mineralizado: antisoviético, antiindio, chauvinista y panamericanista a la vez; imaginario conductor del pueblo; poeta y orador, ensayista y filósofo entre sueños; sociólogo, ideólogo y replicante en la fantasía de José Enrique Rodó; polemista de "fama universal" que se trenzó con Wallace, Papini, Toynbee, Madariaga, Sánchez, Chateaubriand...; sólo que los nombrados no se percataron de las polémicas que Diez de Medina decía sostener con ellos; ni siquiera supieron algunos de su existencia... en Bolivia, destruyó según dogmática creencia suya, en trascendencia lances polémicos a Arguedas, Tamayo, Canelas. Sólo sigue gravitando en la conciencia boliviana con el mismo peso y la fuerza de una montaña hierática (Reinaga, 1964: 161).

Según Portanda (1978), Diez de Medina ha polemizado y refutado a los siguientes escritores bolivianos: Alcides Arguedas, Franz Tamayo, Demetrio Canelas, Augusto Céspedes, Joaquín Espada y Eduardo Arze Quiroga. Y a los siguientes extranjeros: Giovanni Papini, Arnold Toynbee, Luis Alberto Sánchez, Salvador de Madariaga, Charles Arnade, Ramón Menéndez Pelayo, John Masters y el Time de Nueva York y Assis de Chateaubrind (Portanda, 
1978: 219). Lo más llamativo en esta lista de controversias e impugnaciones de Fernando Diez de Medina es que no se mencione a Fausto Reinaga. ¿Por qué? ¿Fue el más duro de sus críticos?

Según el testimonio de Hilda Reinaga, sobrina de Fausto, "el silencio total" fue la respuesta de Diez de Medina a la crítica de Reinaga, expuesta en El indio y el cholaje boliviano. Proceso a Fernando Diez de Medina. Además, Diez de Medina hizo la bajeza de hacer decomisar el libro El indio y el cholaje boliviano de la librería Juventud, donde se comercializaba. Hilda misma nos contó que los libros después de la incautación se habrían incinerado.

Hay otro pasaje conflictivo de la relación de Fernando Diez de Medina con Reinaga. Diez de Medina publicó en 1954 un libro titulado Literatura boliviana. En este texto cita a Reinaga de la siguiente manera: "El Belzu, de Fausto Reinaga, es un ensayo ditirámbico disparatado, tan alejado de la verdad histórica como del equilibrio crítico" (Diez de Medina, 1954: 379).

Sin embargo, en ediciones posteriores de este libro se excluye el párrafo mencionado, aunque queda como constancia de ella en el "Índice Alfabético de Nombres Citados", como Reinaga, Fausto: 347. ¿Por qué se ha eliminado el párrafo citado en la publicación de 1954 en ediciones posteriores? ¿Cómo explicar esta actitud? ¿Tal vez un simple error de imprenta?

El asunto está muy claro: en 1954 Reinaga aún no critica a Diez de Medina; pero en las posteriores ediciones (por ejemplo de 1980), Diez de Medina, al verse criticado por Reinaga, elimina la referencia a la obra.

En compilaciones más especializadas sobre el ensayo y el pensamiento político boliviano, como la de Juan Albarracín Millán, que publicó cinco tomos, ${ }^{4}$ y la de Guillermo Francovich, se asume la misma actitud de silencio. Francovich es considerado como uno de los filósofos bolivianos más destacados, y algún interesado supondría encontrar algo sobre Reinaga en algunas de sus obras sobre la filosofía y al pensamiento boliviano del siglo XX; ${ }^{5}$ pero no es así. Por ejemplo, en su libro El pensamiento boliviano en el siglo XX (1956) cita a autores como Alcides Arguedas, Franz Tamayo, Gustavo Navarro o Tristán Marof, Fernando Diez de Medina y muchos otros; pero no

4 Los libros de Juan Albarracín son: el tomo I, Orígenes del pensamiento social contemporáneo de Bolivia (1976), el II: El gran debate. Positivismo e irracionalismo en el estudio de la sociedad boliviana (1978), el III: La sociedad opresora. Corrientes eclécticas de transición del positivismo al marxismo (1979); el IV: Sociología indigenal y antropología telurista (1982), y el tomo V: Geopolítica, populismo y teoría sociotricronopanorámica (1982).

5 Otra obra de Francovich es La filosofía en Bolivia, 1947/1987. Supay, 1939/1971. 
a Reinaga. Posiblemente una explicación sea que Reinaga haya criticado a Francovich en su libro La intelligentsia del cholaje boliviano de 1967.

En esta breve revisión sobre el impacto de las obras de Reinaga en las compilaciones bibliográficas más importantes, nos topamos con que amigos muy cercanos de Reinaga y de estilos narrativos similares sobre la interpretación de la realidad boliviana son frecuentemente citados como parte fundamental de la producción intelectual del pensamiento boliviano. Es el caso de Gustavo Navarro o Tristán Marof y algunos otros. Ante este enfoque bibliográfico boliviano preguntamos: ¿Qué es ser intelectual en Bolivia? ¿Es cuestión de clase, de raza? ¿Los indios quechuaymara como Reinaga no tienen derecho a ser reconocidos como escritores e intelectuales?

\section{CONCLUSIÓN}

Nos aproximamos a cómo Fausto Reinaga enfrentó esa política intelectual colonialista a lo largo de varios años, ejemplificada con su interpelación al indigenista Fernando Diez de Medina. La respuesta a sus cuestionamientos fue el silencio. También indagamos el silencio de una mayoría de los compiladores bolivianos sobre los escritores nacionales, como el ensayo, la política y la crítica, quienes lo excluyeron casi de todo quehacer intelectual.

Chuqipayu marka, La Paz, Lapaka phaxsi,

Noviembre, 2013.

\section{BiBLIOGRAFÍA}

ALBARRACÍN MILLÁN, J. (1976); Orígenes del pensamiento social contemporáneo de Bolivia, t. I. La Paz: Universo.

, (1978); El gran debate. Positivismo e irracionalismo en el estudio de la sociedad boliviana, t. II. La Paz: Universo.

(1979); La sociedad opresora. Corrientes eclécticas de transición del positivismo al marxismo. t. III. La Paz: Universo.

, (1982); Sociología indigenal y antropología telurista. t. IV. La Paz: Universo. 
ALBARRACÍN MILLÁN, J. (1982); Geopolítica populismo y teoría sociotricronopanorámica, t. V. La Paz: Universo.

ALVIZURI, V. (2009); La construcción de la aymaridad. Una historia de la etnicidad en Bolivia (1952-2006). Santa Cruz: El País.

CONDARCO MORALES, R. (1983); Zárate, el "Temible" Willka. Historia de la rebelión indígena de 1899 en la República de Bolivia. La Paz: Renovación.

DIEZ de MEDINA, F. (1935); El velero matinal. La Paz: América.

, (1947); Thunupa. Ensayos. La Paz: Gisbert y Cía.

, (1948); Pachakuti y otras páginas polémicas. La Paz: Año Inaugural. , (1950); Nayjama. Introducción a la mitología andina. Madrid: Paraninfo. , (1950); Siripaka. La Paz.

, (1954); Sariri. La Paz: Tejerina.

, (1954); Literatura boliviana. Introducción al Estudio de las letras nacionales del tiempo mítico a la producción contemporánea. Madrid: Aguilar. , (1969); Mateo Montemayor. La Paz-Cochabamba: Amigos del Libro. , (1970); Ollanta, el jefe Colla. La Paz-Cochabamba: Amigos del Libro. , (1972); El general del pueblo. La Paz-Cochabamba: Amigos del libro. , (1973); La teogonía andina. La Paz: H. Municipalidad de La Paz. (1980); Literatura boliviana. Introducción al Estudio de las letras nacionales del tiempo mítico a la producción contemporánea. La Paz/Cochabamba: Los Amigos del Libro. (1980); Franz Tamayo. Hechicero del Ande. La Paz: Juventud.

FRANCOVICH, G. (1987); La filosofía en Bolivia, La Paz: Juventud.

GUZMÁN, A. (1975); Poetas y escritores de Bolivia. La Paz-Cochabamba: Amigos del Libro.

MATA, G. H. (1968); Fausto Reinaga. Akapi Jachiaj. La Paz: Ediciones PIB.

MATÍNEZ ACCHINI, L. (1999); Indios y gamonales: aportes de Fausto Reinaga y Fernando Diez de Medina en la formación del pensamiento social boliviano, t. II, pp. 73-76, XIII Reunión anual de Etnología. Identidades, globalización o etnocidio. La Paz: Musef.

OLIVA OLIVA, M. E. (2010); La negritud, el indianismo y sus intelectuales: Aimé Césaire y Fausto Reinaga. Tesis de Magister en Estudios Latinoamericanos, Santiago: Universidad de Chile, Facultad de Filosofía y Humanidades, Escuela de Postgrado, Centro de Estudios Culturales Latinoamericanos.

OPORTO ORDÓÑEZ, L. (1994); “Fausto Reinaga, Rupaj Katari. Político y filósofo Amauta, 1906-1994”. En Presencia literaria, 18 de septiembre. La Paz. 
OPORTO ORDÓNEZ, L. y REINAGA, H. (1994); Bio-bibliografía de José Fausto Reinaga, Rupaj Katari. 1906-1994, Presencia Literaria. 2 de octubre.

PORTANDA RAMOS, M. (1978); Fernando Diez de Medina. Proyecciones de su obra intelectual. La Paz: Fundación Manuel Vicente Ballivián.

SALAS, E. M. (2005); Análisis al pensamiento de Fausto Reinaga. Oruro: El Amauta.

SILES GUEVARA, J. (1975); Las cien obras capitales de la literatura boliviana. La Paz/Cochabamba: Los Amigos del Libro.

STEPHENSON, M. (2003) "El uso de dualismos y género sexual en la formulación del discurso indianista de Fausto Reinaga", en Josefa Salmón y Guillermo Delgado, eds. Identidad, ciudadanía y participación popular desde la colonia al siglo XX. La Paz: Plural.

REINAGA, F. (1978); El pensamiento amautico. La Paz: PIB. , (1974); América india y Occidente. La Paz: PIB. , (1971); Tesis india. La Paz: PIB. (1964); El indio y el cholaje boliviano. Proceso a Fernando Diez de Medina. La Paz: PIAKK. , (1967); La "intelligentsia” del cholaje boliviano. La Paz: PIB. , (1953); Belzu, precursor de la revolución nacional. La Paz: Rumbo sindical. , (1970); La revolución India. La Paz: PIB.

\section{Anexo. Publicaciones de Fausto Reinaga. 1940-1991}

1940. Mitayos y Yanaconas. Oruro: HAM. Imp. Mazuelos.

1949. Victor Paz Estenssoro. La Paz: CEC.

1952. Nacionalismo Boliviano, (Ruy Ripaj). La Paz.

1953. Belzu. precursor de la revolución nacional. La Paz: Rumbo Sindical.

1953. Tierra y libertad. La revolución nacional y el indio. La Paz: Rumbo Sindical. 1956. Franz Tamayo y la Revolución Boliviana. La Paz: Casegural.

1956. Revolución, cultura y crítica. La Paz: Casegural.

1960. Alcides Arguedas. La Paz: Talleres Gráficos Guttemberg.

1960. El sentimiento mesiánico del pueblo ruso. La Paz: Ediciones Sindicato de Escritores Revolucionarios.

1960. España. La Paz.

1964. El indio y el cholaje boliviano. Proceso a Fernando Diez de Medina. La Paz: Partido Indio de Aymaras y Kechuas (PIAK). 
1967. La "intelligentsia" del cholaje Boliviano. La Paz: Partido Indio de Bolivia (PIB).

1968. El indio y los escritores de América. La Paz: PIB.

1969 (2001). La revolución india. La Paz: PIB.

1970. Manifiesto del Partido Indio de Bolivia. La Paz: PIB.

1971. Tesis india. La Paz, PIB.

1974. América india y Occidente. La Paz: PIB

1974. Poder indio y Occidente. La Paz: PIB.

1978. El pensamiento amáutico. La Paz: PIB.

1978. Indianidad. La Paz: PIB.

1978. La razón y el indio. La Paz: PIB.

1980. ¿Qué hacer?. La Paz: Comunidad Amáutica Mundial (CAM).

1981. Bolivia y la revolución de las Fuerzas Armadas. La Paz: CAM.

1981. El hombre. La Paz: CAM.

1981. La era de Einstein. La Paz: CAM.

1981. La revolución amáutica. La Paz: CAM.

1982. Podredumbre criminal del pensamiento europeo. La Paz: CAM.

1983. Sócrates y yo. La Paz: CAM.

1984. América: 500 años de esclavitud, hambre y masacre.

1984. Europa prostituta asesina. Congreso Mundial de los Intelectuales del Tercer Mundo. La Paz: CAM.

1986. Crimen. Sócrates, Cristo, Marx, Churchill, Rossevelt, Stalin, Hitler, Reagan, Gorvachov. La Paz: CAM.

1991. El pensamiento indio. La Paz: CAM. 